\title{
IS THERE ANY DIFFERENCE IN THE PROGNOSIS FOR PATIENTS WITH PRIMARY OSTEOSARCOMA WITH A POOR RESPONSE TO NEOADJUVANT CHEMOTHERAPY BETWEEN HUVOS GRADES I AND II?
}

Rosalvo Zósimo Bispo Júnior' ${ }^{1}$ Olavo Pires de Camargo²

\section{ABSTRACT}

Objective: Would there be any difference in the prognosis for patients who presented, for example, $8 \%$ or $88 \%$ tumor necrosis induced by chemotherapy, even though both individuals were considered to be poor responders? The aim of this study was to compare the prognoses for different histological grades (Huvos grade I versus grade II), consequent to chemotherapy, among patients with primary osteosarcoma that was not metastatic at diagnosis. Methods: Twenty-four patients admitted to a referral center between 2000 and 2004 were selected for the study. The accumulated chances of survival were calculated using the Kaplan-Meier technique. Huvos grades I and II for necrosis consequent to chemotherapy were evaluated as variables in order to determine their prognostic value, in relation to local recurrence-free survival, metastasis-free survival and overall survival, using the log-rank test. Results: Comparing Huvos grades I and II, the following P values for survival were attained: local recurrence-free survival $(\mathrm{P}=0.731)$, metastasis-free survival $(P=0.596)$ and overall survival $(P=0.669)$. Conclusion: In this series, Huvos grades I and II did not have any comparative prognostic value and had similar behavior.

Keywords - Bone Neoplasms/pathology; Drug Therapy; Prognosis; Survivors

\section{INTRODUCTION}

Osteosarcoma is an aggressive malignant type of neoplasia of mesenchymal origin that is characterized by irregular formation of immature bone and production of osteoid matrix and malignant stromal fusiform cells ${ }^{(1)}$. It is one of the commonest types of primary non-hematopoietic bone sarcoma ${ }^{(2-4)}$, albeit uncommon if compared with neoplasia in general $^{(2)}$.

In the United States, the annual incidence of osteosarcoma is 6.5 patients per million children, or 900 new cases per year ${ }^{(5)}$. In Brazil, the real incidence is difficult to determine because of the lack of adequate records. However, it has been estimated that there are 350 new cases per year ${ }^{(6)}$.

The appropriate treatment for high-grade malignant osteosarcoma consists of a multidisciplinary approach based on preoperative chemotherapy (neoadjuvant), surgery and postoperative chemotherapy (adjuvant). A recent multi-institutional retrospective study ${ }^{(7)}$ suggested that a combination of surgery and chemotherapy seems to be the standard choice of treatment and, likewise, chemotherapy may function better if used both preoperatively and postoperatively.

The prognosis for patients with osteosarcoma has improved considerably over recent decades. This has

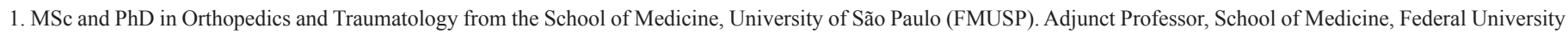
of Campina Grande (UFCG), Campina Grande, Brazil.

2. Titular Professor, Department of Orthopedics and Traumatology, School of Medicine, University of São Paulo (DOT/FMUSP), São Paulo, Brazil.

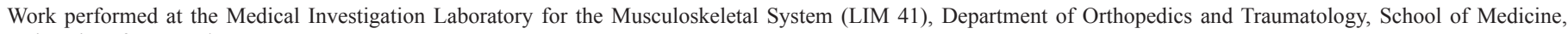
University of São Paulo

Correspondence: Campus Universitário - BR-230, km 22 - Caixa Postal 318 - 58053-000 - João Pessoa, PB, Brasil. E-mail: zosimo_jr@yahoo.com.br Work received for publication: March 30, 2010; accepted for publication: July 17,2010.

The authors declare that there was no conflict of interest in conducting this work 
occurred through adequate staging of these tumors, improved imaging methods and, especially, polychemotherapy. Today, the five-year disease-free survival rate has reached $60-70 \%$, using the most recent chemotherapy protocols ${ }^{(8-12)}$.

Poor histological response to preoperative chemotherapy, as assessed by the degree of necrosis in the surgical specimen, is also considered to be one of the most important unfavorable prognostic factors relating to the survival of osteosarcoma patients ${ }^{(6,7,8,13-21)}$. In the literature, the grading method that is still most used is the one described by Huvos et $\mathrm{al}^{(22)}$, in 1977. In this, these authors divided the degree of necrosis into four types: grade I, no effect from chemotherapy; grade II, partial response with more than $50 \%$ necrosis; grade III, more than $90 \%$ necrosis, with a viable tumor present; or grade IV, without a viable tumor. According to Rosen et al ${ }^{(23)}$, patients are considered to be, respectively, good or poor responders if they present tumor necrosis in the resected specimen greater than or less than $90 \%$. Based on these classifications, the question that we pose is the following: Would there be a difference in prognosis between patients who presented, for example, 8 or $88 \%$ tumor necrosis induced by chemotherapy, even though both of these cases would be considered to be poor responders?

The aim of the present study was to compare the prognosis for the histological grading (Huvos grade I versus grade II) after the effect of chemotherapy, among patients with primary osteosarcoma that was not metastatic at the time of diagnosis, with treatment in accordance with Study V of the Brazilian Cooperative Group for Osteosarcoma Treatment (GBTO).

\section{SAMPLE AND METHODS}

The medical files of patients with an anatomopathological diagnosis of primary osteosarcoma made by the orthopedic oncology group of a referral clinic between 2000 and 2004 were analyzed. These patients were treated in accordance with Study V of the Brazilian Cooperative Group for Osteosarcoma Treatment (GBTO), with cisplatin (120 mg/ $\mathrm{m}^{2} /$ cycle), ifosfamide $\left(13.5 \mathrm{mg} / \mathrm{m}^{2} /\right.$ cycle $)$ and Adriamycin ${ }^{\circ}\left(80 \mathrm{mg} / \mathrm{m}^{2} /\right.$ cycle), totaling nine cycles for patients who were non-metastatic at diagnosis. The analysis on the variable was performed on 24 medical files of patients who underwent treatment for osteosarcoma. The following inclusion criteria were used: (a) Anatomopathological confirmation of primary osteosarcoma: all the slides were reviewed by a pathologist who was a specialist on musculoskeletal tissues; (b) Patients who were all treated (during the study period) using the same protocol for neoadjuvant chemotherapy (Study V, GBTO); (c) Patients who underwent operations at our clinic for local control of the primary tumor after the chemotherapy; (d) Patients who were considered to be poor responders to the preoperative chemotherapy that was instituted (grades I and II according to the classification of Huvos et $\mathrm{al}^{(22)}$. The following exclusion criteria were used: (a) Presence of pulmonary or bone metastases at the initial assessment; (b) Presence of tumors with low-grade malignity; (c) Patients who did not undergo neoadjuvant chemotherapy or who died during this therapy; (d) Patients who had undergone some form of treatment for the tumor prior to registration at our clinic. The anatomopathological review was conducted using paraffin blocks containing tumor fragments from the surgical specimen, in all the cases.

This protocol was approved by our institution's research ethics committee.

\section{STATISTICAL ANALYSIS}

The study database was compiled in a spreadsheet within the Excel 2007 software for Windows, after applying a protocol to the medical files. The statistical analyses were performed using the SPSS statistical software, version 12.0 (SPSS Inc., Chicago, IL, USA).

The accumulated survival probabilities were calculated by means of the Kaplan-Meier technique. Huvos grades I and II, for the degree of necrosis after the effect of the chemotherapy, were evaluated as variables to determine their prognostic value in relation to survival free from local recurrence, survival free from metastasis and overall survival, using the Log-Rank test. Statistical significance was defined as $\mathrm{p}<0.05$.

\section{RESULTS}

In the sample of 24 cases, the histological responses to preoperative chemotherapy according to the criteria of Huvos et al. (1977) comprised 18 cases $(75.0 \%)$ with grade I and six cases $(25.0 \%)$ with grade II (Figure 1). The mean length of follow-up among 
the patients with non-metastatic osteosarcoma in our sample was 39.08 months (with a standard deviation of 28.16 months and median of 47 months), ranging from two to 83 months.

The prognostic values of the degrees of tumor necrosis after chemotherapy were evaluated based on the local recurrence-free survival (LRFS), metastasis-free survival (MFS) and overall survival (OS) curves.

The degrees of tissue necrosis after chemotherapy (Huvos I versus Huvos II) did not reach statistically significant levels and were not considered to be prognostic factors for LRFS (Figure 2).

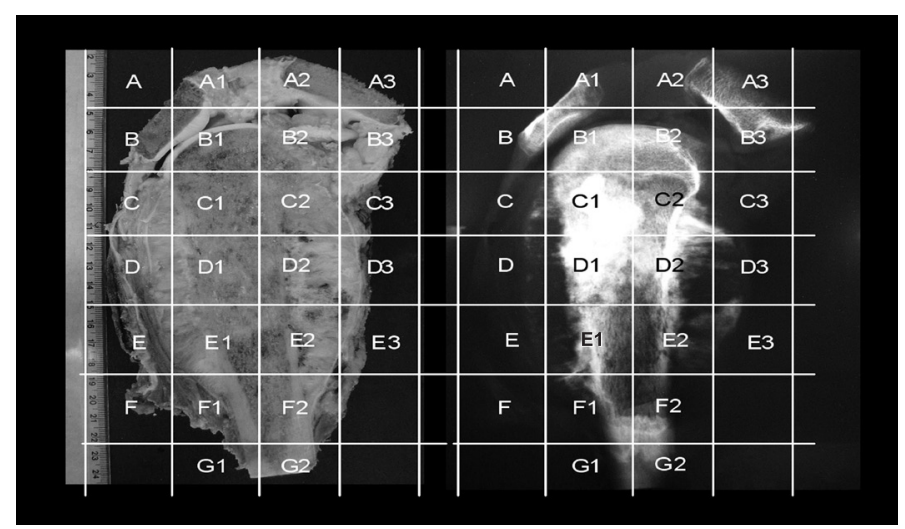

Figure 1 - Macroscopic preparation of a surgical specimen together with its radiograph, ready for microscopic analysis (histopathology) on tumor after chemotherapy.

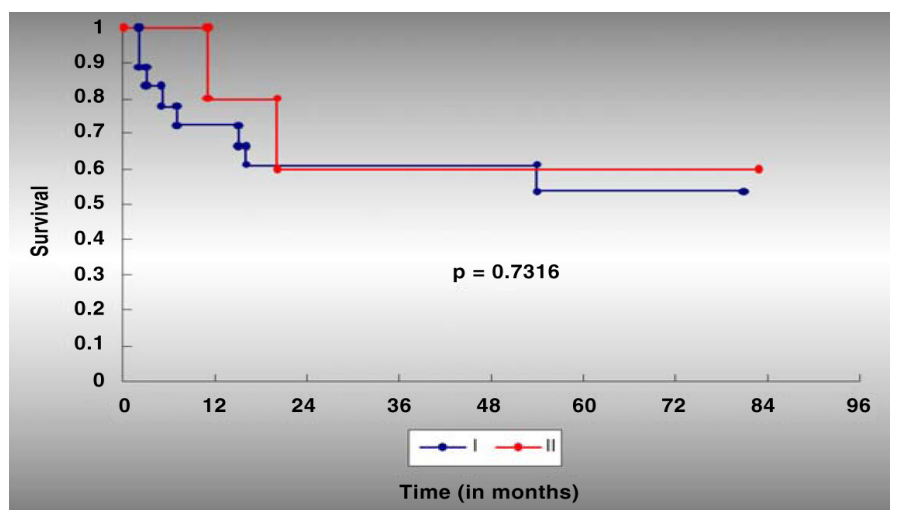

Figure 2 - Local recurrence-free survival curve in months for the 24 patients with primary non-metastatic osteosarcoma at diagnosis, according to the degree of tumor necrosis after the effect of chemotherapy (Huvos I and II).

Comparing the degrees of tumor necrosis (Huvos I versus Huvos II), they did not reach statistically significant levels and were not considered to be prognostic factors for MFS (Figure 3).

The anatomopathological grading (Huvos I versus Huvos II) also did not influence OS (Figure 4).

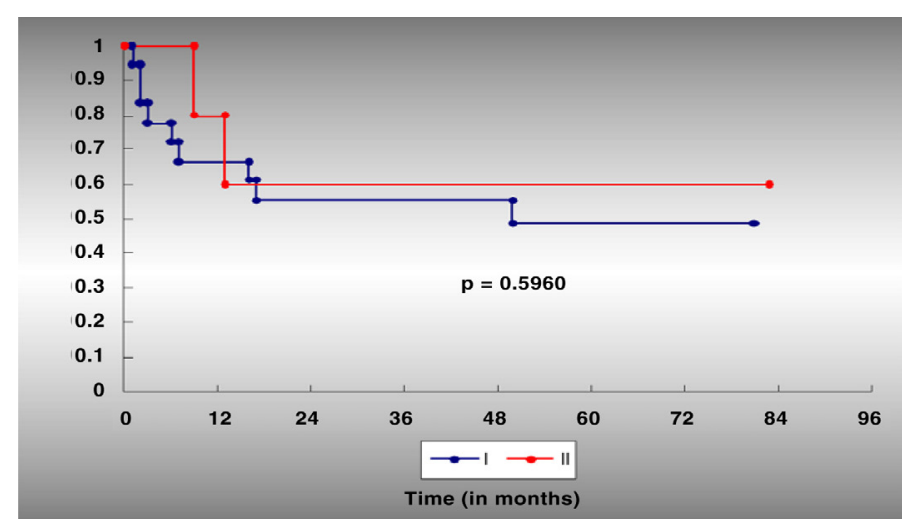

Figure 3 - Metastasis-free survival curve in months for the 24 patients with primary non-metastatic osteosarcoma at diagnosis, according to the degree of tumor necrosis after the effect of chemotherapy (Huvos I and II).

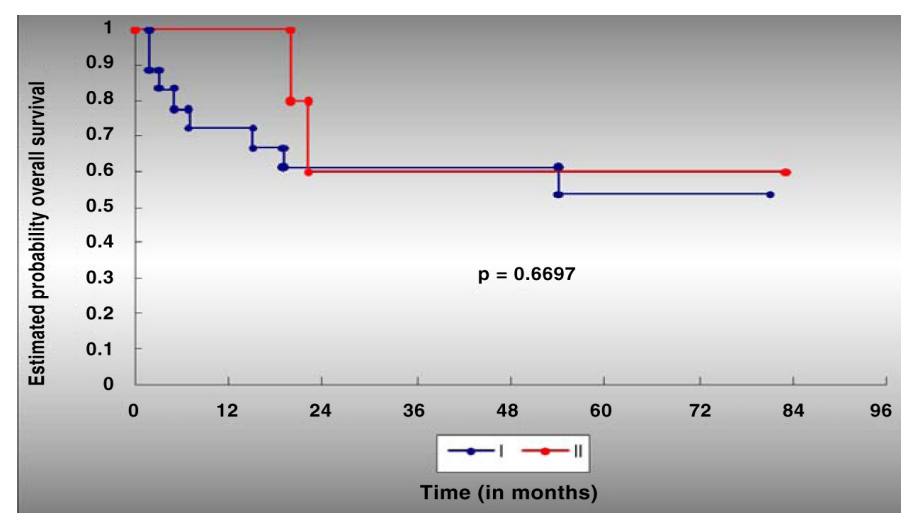

Figure 4 - Overall survival curve in months for the 24 patients with primary non-metastatic osteosarcoma at diagnosis, according to the degree of tumor necrosis after the effect of chemotherapy (Huvos I and II).

\section{DISCUSSION}

Despite the relative rarity of osteosarcoma, several studies $^{(7,12,15-17,20,21,24-27)}$, including some within our setting, have sought to identify risk factors that might influence the natural history of this tumor and the prognosis for patients.

The efficacy of chemotherapy and its impact on the survival of patients with osteosarcoma are well documented $^{(6,7)}$. There seems to be almost a consensus in the literature ${ }^{(7,8,12,13,17-19)}$ that the degree of tumor necrosis induced by preoperative chemotherapy is an important prognostic factor in relation to the survival of patients with primary osteosarcoma. This has also been seen in Brazilian studies ${ }^{(6,15,21,24,25)}$. Patients whose resected surgical specimens present tumor necrosis greater than $90 \%$ (Huvos types III and IV) have a better prognosis than shown by those whose specimens present tumor necrosis of less than 90\% (Huvos 
types I and II). Thus, we compared the poor responders ( $<90 \%$ tumor necrosis): Huvos type I $(<50 \%)$ versus type II (50 to $90 \%$ ), in relation to the survival parameters (LRFS, MFS and OS), and observed that these are not adverse factors.

In this study, stratification into groups I and II, following the Huvos criteria, was not shown to be necessary, given the similar behavior presented by the two groups, in the statistical analysis. These statistical results suggest that groups I and II presented homogenous behavior, including in relation to the therapeutic responses made, thus confirming a trend in the worldwide literature, in which the cutoff point is $90 \%$ in the histological analysis.

A preliminary evaluation of this study seems to demonstrate that patients with tumor necrosis of Huvos grades I and II after neoadjuvant chemotherapy have similar prognostic behavior, despite the wide difference in percentage range in these two groups when summed (0 to $90 \%$ ). However, further studies are needed in order to establish a comparative analysis between Huvos groups I and II and thereby corroborate the above affirmation.

\section{CONCLUSION}

In this series, comparison between Huvos grades I and II showed that they did not have any prognostic value in relation to any of the survival parameters studied (LRFS, MFS and OS), since they behaved similarly.

\section{REFERENCES}

1. Schajowicz F, Sissons HA, Sobin LH. The World Health Organization's histologic classification of bone tumors. A commentary on the second edition. Cancer. 1995;75(5):1208-14.

2. Dorfman HD, Czerniak B. Bone cancers. Cancer. 1995;75(Suppl 1):203-10.

3. Dorfman HD, Czerniak B. Bone tumors. St Louis: Mosby; 1998.

4. Raymond AK, Ayala AG, Knuutila S. Secondary osteosarcoma. In: Fletcher CDM, Unni KK, Mertens F, editors. Pathology and genetics of tumours of the soft tissues and bones. Lyon: IARC Press; 2002. p. 264-70.

5. American Cancer Society. Cancer Reference Inforamtion. Detailed Guide: Osteosarcoma. What Are The Key Statistics About Osteosarcoma? Dispinível em: http://www.cancer.org/docroot/CRI/content/CRI_2_4_1X_What_are_the_key_statistics_for_osteosarcoma_52.asp?sitearea. Acesso em 08 de outubro de 2009.

6. Petrilli AS, de Camargo B, Filho VO, Bruniera P, Brunetto AL, Jesus-Garcia R, et al. Results of the Brazilian Osteosarcoma Treatment Group Studies III and IV: prognostic factors and impact on survival. J Clin Oncol. 2006;24(7):1161-8.

7. Pakos EE, Nearchou AD, Grimer RJ, Koumoullis HD, Abudu A, Bramer JA, et al. Prognostic factors and outcomes for osteosarcoma: an international collaboration. Eur J Cancer. 2009;45(13):2367-75.

8. Meyers PA, Heller G, Healey J, Huvos A, Lane J, Marcove R, et al. Chemotherapy for nonmetastatic osteogenic sarcoma: the Memorial Sloan-Kettering experience. J Clin Oncol. 1992;10(1):5-15.

9. Bacci G, Picci P, Ferrari S, Ruggieri P, Casadei R, Tienghi A, et al. Primary chemotherapy and delayed surgery for nonmetastatic osteosarcoma of the extremities. Results in 164 patients preoperatively treated with high doses of methotrexate followed by cisplatin and doxorubicin. Cancer. 1993;72(11):3227-38.

10. Provisor AJ, Ettinger LJ, Nachman JB, Krailo MD, Makley JT, Yunis EJ, et al. Treatment of nonmetastatic osteosarcoma of the extremity with preoperative and postoperative chemotherapy: a report from the Children's Cancer Group. J Clin Oncol. 1997;15(1):76-84.

11. Souhami RL, Craft AW, Van der Eijken JW, Nooij M, Spooner D, Bramwell $\mathrm{VH}$, et al. Randomised trial of two regimens of chemotherapy in operable osteosarcoma: a study of the European Osteosarcoma Intergroup. Lancet. 1997;350(9082):911-7.

12. Ferrari S, Bertoni F, Mercuri M, Picci P, Giacomini S, Longhi A, Bacci G. Predictive factors of disease-free survival for non-metastatic osteosarcoma of the extremity: an analysis of 300 patients treated at the Rizzoli Institute. Ann Oncol. 2001;12(8):1145-50.

13. Hudson M, Jaffe MR, Jaffe N, Ayala A, Raymond AK, Carrasco H, et al. Pediatric osteosarcoma: therapeutic strategies, results, and prognostic factors derived from a 10-year experience. J Clin Oncol. 1990;8(12):1988-97.

14. Link MP, Goorin AM, Horowitz M, Meyer WH, Belasco J, Baker A, et al. Ad-

juvant chemotherapy of high-grade osteosarcoma of the extremity. Updated results of the Multi-Institutional Osteosarcoma Study. Clin Orthop Relat Res. $1991 ;(270): 8-14$.

15. Petrilli AS, Gentil FC, Epelman S, Lopes LF, Bianchi A, Lopes A, et al. Increased survival, limb preservation, and prognostic factors for osteosarcoma. Cancer. 1991;68(4):733-7.

16. Glasser DB, Lane JM, Huvos AG, Marcove RC, Rosen G. Survival, prognosis, and therapeutic response in osteogenic sarcoma. The Memorial Hospital experience. Cancer. 1992;69(3):698-708.

17. Davis AM, Bell RS, Goodwin PJ. Prognostic factors in osteosarcoma: a critical review. J Clin Oncol. 1994;12(2):423-31.

18. Saeter G, Elomaa I, Wahlqvist $Y$, Alvegård TA, Wiebe T, Monge $O$, et al. Prognostic factors in bone sarcomas. Acta Orthop Scand Suppl. 1997;273:156-60.

19. Bacci G, Ferrari S, Longhi A, Forni C, Zavatta M, Versari M, Smith K. High-grade osteosarcoma of the extremity: differences between localized and metastatic tumors at presentation. J Pediatr Hematol Oncol. 2002;24(1):27-30.

20. Bielack SS, Kempf-Bielack B, Delling G, Exner GU, Flege S, Helmke K, et al. Prognostic factors in high-grade osteosarcoma of the extremities or trunk: an analysis of 1,702 patients treated on neoadjuvant cooperative osteosarcoma study group protocols. J Clin Oncol. 2002;20(3):776-90.

21. Rech A, Castro CG Jr, Mattei J, Gregianin L, Di Leone L, David A, et al. [Clinical features in osteosarcoma and prognostic implications]. J Pediatr (Rio J). 2004;80(1):65-70.

22. Huvos AG, Rosen G, Marcove RC. Primary osteogenic sarcoma: pathologic aspects in 20 patients after treatment with chemotherapy en bloc resection, and prosthetic bone replacement. Arch Pathol Lab Med. 1977;101(1):14-8.

23. Rosen G, Caparros B, Huvos AG, Kosloff C, Nirenberg A, Cacavio A, et al. Preoperative chemotherapy for osteogenic sarcoma: selection of postoperative adjuvant chemotherapy based on the response of the primary tumor to preoperative chemotherapy. Cancer. 1982;49(6):1221-30.

24. Jesus-Garcia R, Consentino E, Camargo OP, Baptista PPR, Croci AT, Korukian $\mathrm{M}$ et al. Tratamento ortopédico do osteossarcoma. Grupo cooperativo brasileiro de tratamento do osteossarcoma. Rev Bras Ortop. 1996;31(11):871-8.

25. Cassone AE, Gonçalves JCB, Silva AAM, Epelman S, Amstalden EMI.Tratamento multidisciplinar do osteossarcoma. Rev Bras Ortop. 1998;33(11):835-40.

26. Bispo Júnior RZ, Camargo OP. Prognostic factors for the survival of patients diagnosed with primary non-metastatic osteosarcoma with a poor response to neoadjuvant chemotherapy. Clinics. 2009;64(12):1177-86.

27. Bispo Júnior RZ. Fatores prognósticos da sobrevida no osteossarcoma primário: grau I versus II de Huvos [tese]. São Paulo: Universidade de São Paulo. Faculdade de Medicina; 2009. 